\title{
Differences in School Climate Means: Exploring Contextual Factors among a Sample of Appalachian Youth
}

Shay M. Daily

Follow this and additional works at: https://researchrepository.wvu.edu/etd

\section{Recommended Citation}

Daily, Shay M., "Differences in School Climate Means: Exploring Contextual Factors among a Sample of Appalachian Youth" (2016). Graduate Theses, Dissertations, and Problem Reports. 5429.

https://researchrepository.wvu.edu/etd/5429

This Thesis is protected by copyright and/or related rights. It has been brought to you by the The Research Repository @ WVU with permission from the rights-holder(s). You are free to use this Thesis in any way that is permitted by the copyright and related rights legislation that applies to your use. For other uses you must obtain permission from the rights-holder(s) directly, unless additional rights are indicated by a Creative Commons license in the record and/ or on the work itself. This Thesis has been accepted for inclusion in WVU Graduate Theses, Dissertations, and Problem Reports collection by an authorized administrator of The Research Repository @ WVU. For more information, please contact researchrepository@mail.wvu.edu. 


\title{
Differences in School Climate Means: Exploring Contextual Factors among a Sample of Appalachian Youth
}

\author{
Shay M. Daily, CHES \\ Thesis submitted to the School of Public Health at West Virginia University \\ in partial fulfillment of the requirements for the degree of \\ Master of Public Health in \\ Social and Behavioral Health Sciences
}

Keith J. Zullig, MSPH, PhD, FAAHB, FASHA

Alfgeir L. Kristjansson, PhD

Michael J. Mann, PhD

Department of Social and Behavioral Health Sciences

Morgantown, West Virginia

2016

Keywords: School Climate, School Climate Measure, Every Student Succeeds Act, ESSA, School Health, Appalachian Youth, West Virginia Youth

Copyright 2016 Shay Michael Daily 


\section{Abstract \\ Contextual Characteristics of School Climate among a Sample of Appalachian Youth}

Shay M. Daily, CHES

The Every Student Succeeds Act (ESSA) provides a means for states to streamline current assessment systems and integrate multidimensional measures. The use of comprehensive measures (i.e. school climate) is important in understanding nonacademic factors that influence the quality of a school. There are limited studies which describe how contextual factors influence the learning and behavior of students within demographically homogenous populations, especially from rural settings. Rural populations are characterized to have higher prevalence of multiple social, behavioral, and contextual characteristics that negatively affect their perception of school when compared to their urban counterparts.

The purpose of this study was to examine differences in mother's education and selfreported academic achievement as it relates to race through paired comparisons of School Climate Measure (SCM) means from a sample of Appalachian youth in West Virginia. A total of 1,275 students enrolled in grades 9 - 12 were surveyed using a cross-sectional purposive cluster sample from two high schools.

A factorial ANCOVA with a significance level of .01 was performed to examine main and interaction effects between the independent (mother's education and grades) and dependent variable (instrument mean), while controlling for race.

Findings suggest mother's education and self-reported academic scores in mathematics play a role in influencing how students perceive the climate of the school. Calculated effect sizes within-groups ranged from medium to small, which suggests that school climate matters and is related to maternal education and academic outcomes.

Given the similar differences between the within-groups analysis, further studies with similar methods may point to important implications for the delivery of instruction and school-based interventions that promote positive learning and school quality. 


\section{Table of Contents}

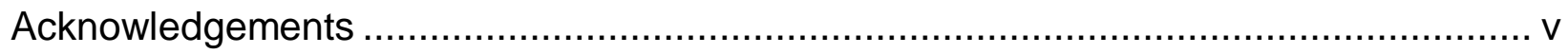

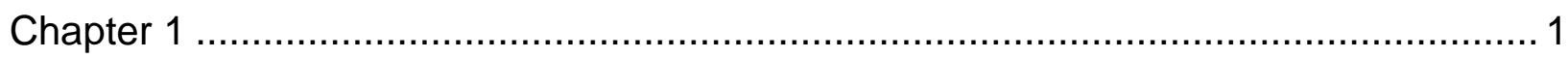

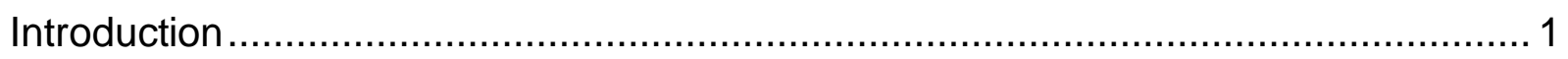

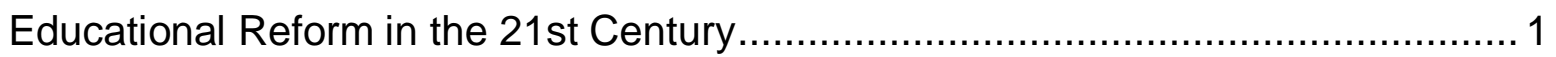

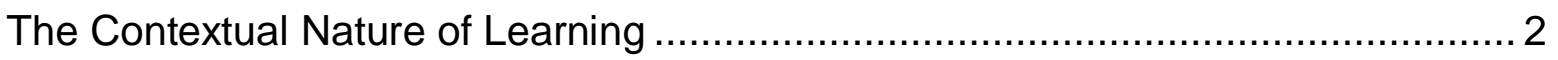

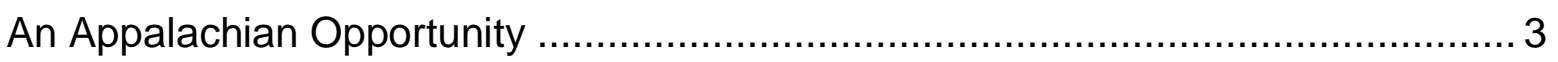

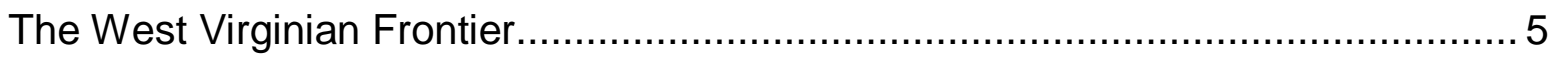

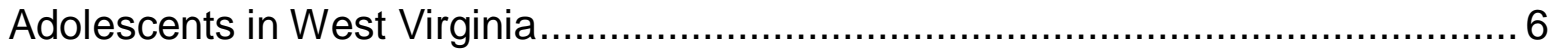

Importance of Mother's Education and Minority Status in West Virginia ................ 7

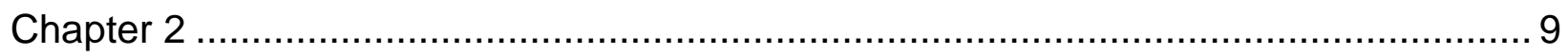

Literature Review of School Climate and Contextual Characteristics ...................... 9

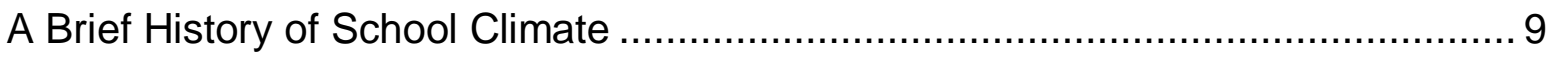

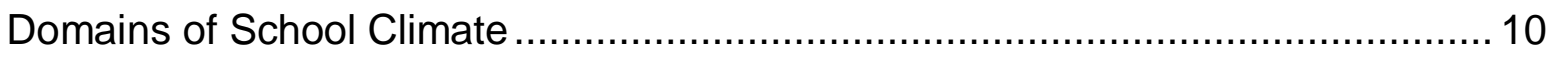

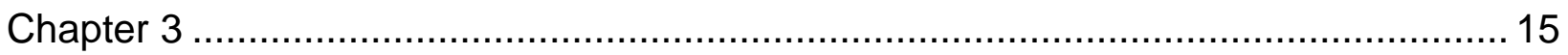

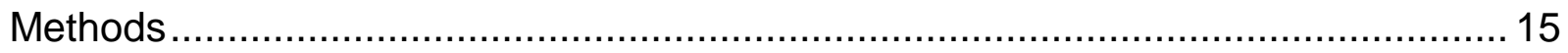

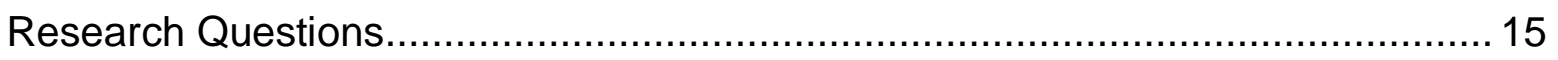

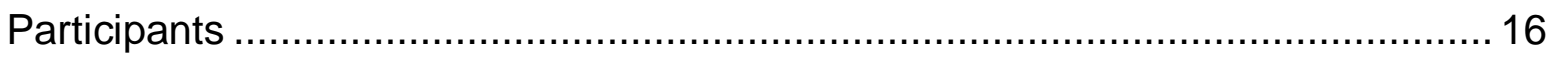

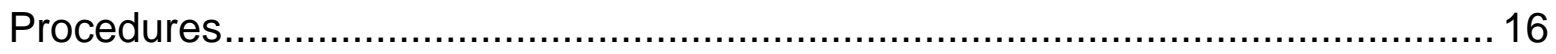

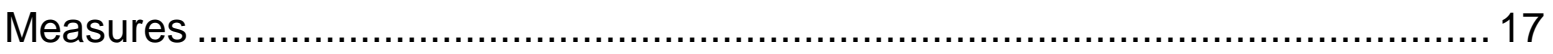

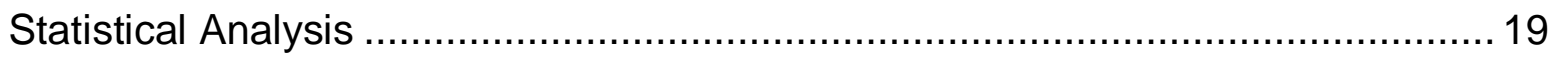

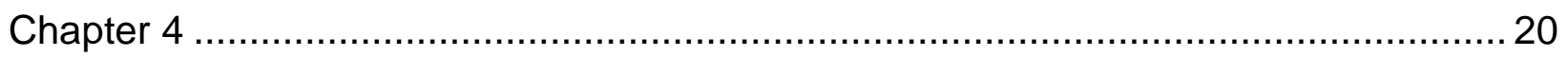

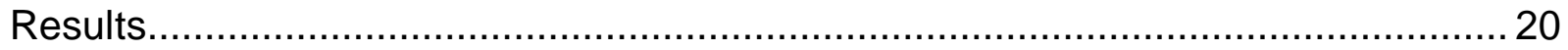


Chapter 5

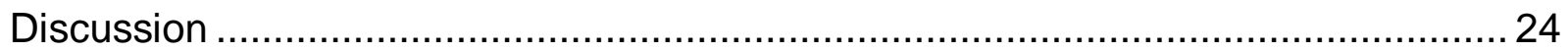

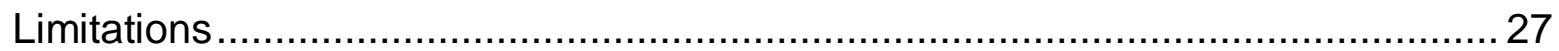

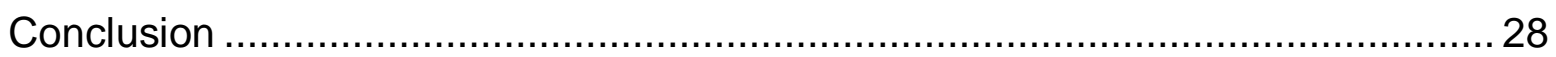

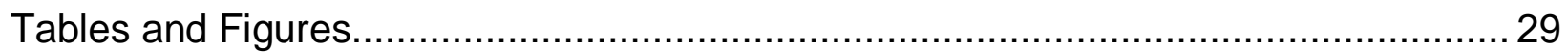

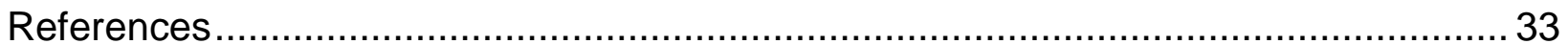




\section{Acknowledgements}

I would like to thank all the members of the thesis committee. Dr. Keith J. Zullig for his encouragement and guidance throughout this project. Dr. Alfgeir L. Kristjansson and Dr. Michael J. Mann for their generosity and lessons on being a better researcher.

I would like to thank Dr. Christa Lilly and Dr. Dustin Long for their kindness and help with the analysis of this project. Most importantly, supporting my ability to be confident in the endeavor.

A special thanks to Janet Hunt for her continued cheering from the sidelines and afternoon tea and chocolate to lift the spirit.

To my dear Katharine for her continued love and support.

To my mother and father. I love you both. 


\section{Chapter 1}

\section{Introduction}

\section{Educational Reform in the 21st Century}

Educational reform has stimulated national dialogue since the passing of the Elementary and Secondary Education Act (ESEA) in 1965 (U.S Department of Education, 2016). For most of the past decade, federal regulations continued to emphasize reading and mathematics as a standard for measuring academic improvement and a schools quality (i.e. No Child Left Behind Act [NCLB], 2001). Although the intention of the No Child Left Behind Act (NCLB) was meant to add educational mobility and accountability, the model granted administrators and teachers little room to expand on school policies and metrics that incorporate non-academic factors (e.g. Socio Economic Status [SES], school climate, and parental support) that impact learning (Martin, Martin, \& Rosengard, 2010). In 2015, Congress and the Obama administration put forward a piece of legislation called "Every Student Succeeds Act (ESSA)" (Every Students Succeeds Act [ESSA], 2015). The ESSA attempts to address many of the shortfalls of NCLB by allowing states more control and flexibility over assessment systems and increased funding for state schools where it is needed (Senate Committee On Health, Education, Labor, and Pensions, 2015). A notable function of the bill is to encourage schools to utilize comprehensive measures (academic and non-academic) that inform administrative decisions about a school's quality. At its core, the ESSA is meant to empower state and local stakeholders by fostering evidence based decisions for improved school system measures (Office of the Press Secretary [OPS], 2015). Based on these central principals, the ESSA provides a means for states to streamline their current assessment systems and move away from the NCLB's standardized mandates (OPS, 2015; The White House, Office of the Press Secretary, 2015). This opportunity will be crucial to research related to contextual factors in education such as school climate. The ESSA's emphasis on reducing the time spent on standardized testing and added non-academic components to school 
measures will potentially reduce knowledge gaps in understanding how contextual factors may shape learning. As such, this would provide state and local administrators with the information needed to integrate evidence-based programs for school, teacher, and student improvement.

\section{The Contextual Nature of Learning}

Conceptual frameworks for understanding learning in education generally stem from cognitive theorist, which emphasize that learning and behavior are an interplay of subjective values between the individual and the environment (physical and social) (Bandura, 2001; Glanz, Rimer, Viswanath, 2008, p. 46). In other words, acquiring a world view or changes in knowledge and skills overtime is dependent on cognitive, emotional, and contextual characteristics of the learning environment (e.g. a school's curriculum, student-teacher relationships, interactions with peers, school policies, parental education, SES, and physical environment) (Illeris, 2004; Ormrod, 2012). For example, a study by Bodovski, Nahum-Shani, \& Walsh (2013) describe in detail the importance of contextual effects on learning and academic achievement. Their research suggests that schools with stronger school climate, while controlling for demographic characteristics (student SES, race/ethnicity composition, school sector, and region), had higher levels of achievement in mathematics over time. Similarly, Willms (2006) performed a comparative analysis of reading and literacy achievement. Willms findings suggest that student-teacher relationships, parental support, and disciplinary climate were associated to higher achievement in reading. Additionally, research has shown that SES is strongly associated with student learning and academic achievement (Lleras, 2008). This is important to note as Willms (2006) suggests that contextual factors like a positive school climate may be able to suppress the effects of SES and support better academic achievement. For example, schools with higher affluence have been described to have stronger positive school climate even with a high portion of enrolled low-SES students (Hoy et al., 2006).

Traditionally, studies similar to the aforementioned, report findings from urban schools with high concentrations of low-SES and minority students (Bodovski et al., 2013). However, there are limited studies which describe how contextual factors 
influence the learning and behavior of students within demographically homogenous populations, especially from rural settings (Istrate, Noveanu, \& Smith, 2006). Based on this social phenomenon, one would assume a standard method or approach would be sufficient to serve demographically similar populations. However, even though people "fit" a similar demographic description they also possess unique characteristics due to their subjective perception and multifaceted ecological experience of the world. As such, minorities living within rural homogenous groups often constitute only a fraction of the total population. Due to their limited visibility, distinctive cultural needs for minorities are often left unaddressed and overlooked (Mueller, Ortega, Parker, Patil, Ashkenazi, 1999). This leads rural minorities to contend with substantially greater social, financial, and ecological barriers than their non-minority counterparts (Mueller et al., 1999).

With the new changes in the ESSA's requirement for comprehensive measures, constructs like school climate can be used to investigate differences in contextual factors among homogenous student populations and distinguish differences among minorities. Understanding these variations, even when subtle, are important as they provide guidance in making accurate conclusions about ways in which school climate may influence educational outcomes. For example, Ito and Smith (2006) found that a school climate where students felt secure, nurtured, and supported was the single best indicator for positive student outcomes among US and Japanese adolescents. However, specifically for US students, males indicated to have less positive outcomes compared to females. As such, revealing this type of information may have implications related to pedagogical strategies in education (Zullig, Koopman, \& Hueber, 2009). With researchers refining their measures collectively with federally supportive legislation, school administrators and community members should find promise in their systematic efforts to improve educational quality, student well-being, and academic achievement.

\section{An Appalachian Opportunity}

The flexibility of the ESSA will be essential to facilitate regional changes across the nation. In particular, the region known as Appalachia may benefit as the states that encompass the area continue to shoulder a significant burden of health disparities (Appalachia Community Cancer Network [ACCN], 2010; CDC, 2009; Meacham, 
Sukpraprut, Taber, \& Mertzger, 2012) and multiple educational hurtles (e.g. low high school graduation rates and high levels of poverty) in the United States (US) (Appalachia Regional Advisory Committee [Appalachia RAC], 2011).

The majority of schools districts in Appalachia reside in rural territories. This is important to note as research has distinguished between rural and urban as an important identifier when reviewing associations to health status, quality of education, and overall quality of life (Bethea, Russell, Cozier, White, McClean, 2012; Ingram \& Franco, 2012). Rural populations are also characterized to have higher prevalence of multiple social, behavioral, and contextual characteristics that affect health when compared to their urban counterparts (Bethea et al., 2012). Epidemiological findings indicate that poverty, lower educational attainment, and access to healthcare are three collective characteristics among rural populations that are definitively associated to the health of individual and subsequently the health of the greater community (Smith \& Holloman, 2011; Haverson, Ma, \& Harner, 2004). Research has also described poverty and lower levels of parental education are associated to poor student performance among rural populations (Stanley, Comello, Edwards, \& Marquart, 2008). Although Appalachia shares many common characteristics of rural settings, Appalachian populations are recognized for their unique cultural features such as being fiercely selfreliant and resistant to external influences (Behringer \& Friedell, 2006; Haverson, Ma, \& Harner, 2004). Because of these cultural characteristics, effective school level research has been limited to clusters of notable success due to deficient cultural competency among researchers (Cleveland, Chambers, Mainus, Powell, \& Skepple, 2012).

Of all the territories within the Appalachian region, only West Virginia is entirely swathed geographically and shares not only borders, but the distinctive cultural attributes of its bordering states. Even though the population is considered demographically homogenous, West Virginians possess multiple underlying contextual characteristics relative to the region in which they live. Thus, some consider West Virginia an Appalachian "melting pot". As such, this cultural diversity may potentially lead to challenges in mitigating health disparities and educational hurtles. 


\section{The West Virginian Frontier}

West Virginia historically is known for its production of natural resources, including energy production and timber. The landscape is quite diverse with the majority of the terrain being entirely mountainous. West Virginia is the second most rural state in the country, with two-thirds of its 1.85 million residents living in communities of less than 2,500 persons (U.S. Census, 2010). National health indicators exhibit the poor health status of most West Virginians who are commonly ranked first, second, or third in the U.S. (United Health Foundation, 2015). Overall, West Virginia has experienced a minimal decrease $(0.1 \%)$ in the population between 2000 and 2010 with $94 \%$ of residents being White. Most residents 25 years and older have at least a high school education (84\%), but this figure dwindles when compared to attaining a Bachelor's Degree or higher (18.7\%). Compared to the nation (29.3\%), West Virginians are less likely to pursue a college education. Similarly, the national per capita income is estimated at $\$ 28,555$ compared to West Virginian residents at $\$ 22,996$ over 12 months (US Census, 2010). Leading to $18 \%$ of adults in West Virginia live below the poverty level compared to $14 \%$ for national estimates (U.S. Census, 2010).

Dissecting the poverty values further, $22.5 \%$ of West Virginia's families with children 18 and under live below the poverty line. In families where a female is the single house holder, $51 \%$ live below the poverty line (U.S. Census, 2010). This important to mention as mother's living in poverty also tend to have lower educational attainment (Brody, Stoneman \& Flor, 1995). Additionally, research by Brody \& Flor (1998) describe how maternal education and parental involvement has strong influence on their child's academic performance. Their findings suggest that, especially among minorities, maternal education is good predictor of student academic achievement and subsequently social status. Similarly, a study by Gordon and Cui (2014) suggest community level poverty may negatively influence parent's involvement and prevent their child from reaching academic milestones. As such, schools are becoming more aware of the importance of understanding contextual factors like parental-involvement and how tailoring school-based programs may mitigate educational disparities and potentially improve the quality of education students receive (Gordon \& Cui, 2014). 


\section{Adolescents in West Virginia}

West Virginia's 55 counties comprise an estimated 229,137 (12.4\%) persons between the ages of 10-19. (U.S. Census, 2010). Based on 2014 estimates, this number has most likely stayed constant over the past several years (U.S. Census, 2014). The most recent enrollment summary report from the West Virginia Department of Education (WVDOE) support the current estimates of the 2014-2015 student enrollment reporting 279,899 students in West Virginia (WVDOE, 2015). The majority of students $(254,093), 91 \%$ identified as White with 144,490 (52\%) male and 135,409 (48\%) female (WVDOE, 2015). Interestingly, based on reporting trends from the WVDOE, rate changes in low socioeconomic status has increased from 149,529 (53\%) in 2011-2012 to 197,927 (71\%) in 2014-2015 (WVDOE, 2015). Of the 757 schools in the state, West Virginia ranks first with (73.8\%) of schools needing assistance from free or reduced-lunch program. In addition, West Virginia also ranks 8th with an estimated 1 in $4(27 \%)$ of children living in poverty (Food Research and Action Center, 2015).

Although this age group represents a minority of the overall population, youth are often more susceptible to risky behaviors due to physical and social environmental factors such as conflicting interpersonal messages from peers and family, bullying, and social media (Mann, Kristjansson, Sigfusdottir, \& Smith, 2014). With multiple environmental and psychosocial influences, it is not surprising that the literature consistently describes this stage of lifespan as "turbulent" (Mann, et al., 2014; Steinberg, 2005).

In tandem with physiological effects, it is well documented that social determinants also play a vital role in adolescent health and wellbeing (Singh \& Ghandour, 2012). For example, socioeconomic status (SES) of a family has been strongly associated to the overall health and well-being of children and adolescents (Singh \& Ghandour, 2012). Likewise, the neighborhood a child grows up in has a strong effect on their perception of life and their behavior within a society (Pebley \& Sastry, 2004; Xue, Leventhal, Brooks-Gunn, \& Earls, 2005). Moreover, several studies provide strong evidence of the relationship between SES and academic achievement (Berkowitz, et al., 2015; Lee, 2002). Not surprisingly, this has led to an increase in 
research from federal and local resources to inform school administration, local health departments, policy makers, and salient stakeholders on what "works best" to properly assess the needs of this population (Jackson \& Davis, 2000). Therefore, incorporating school climate measures can assist in data-informed system-wide interventions, which as suggested by Gregory \& Weinstein (2004) and Berkowitz et al., (2015) may offset the negative influence of low SES status and reduce the achievement gap among students. This in turn should empower stakeholders to recognize quantifiable and attainable outcomes for both schools, student improvement, and overall health (Zullig et al., 2014).

\section{Importance of Mother's Education and Minority Status in West Virginia}

School settings are not only places where students learn from a curriculum, but also where young individuals develop social skills and often experience an increased sense of liberty and personal expression (O'Malley, Voight, Renshaw, \& Eklun, 2015). As such, studies have demonstrated school climate to positively influence children's social environment, academic performance, and mitigate disruptive behaviors (Cohen, McCabe, Michelli, \& Pickeral, 2009). The fact that the great majority of students in West Virginia are White, minority students can be easily overlooked and may face adverse conditions due to the homogeny of the population (Bailey, 2014). Add maternal education as an indicator of poverty and parental school involvement as an influence to poor academic outcomes (Gershoff, 2003) and minority students are potentially at a greater disadvantage than their White counterparts. However, regardless of race, teaching and learning strategies that buffer the effects of student's with low-income need to be implemented to ensure students' academic success. For these reasons, there is a clear need to elevate the understanding of the importance non-academic contextual factors (e.g. how a student is influenced by their school environment) by examining school climate in rural Appalachian populations. Most school climate research includes student's age, sex, race, classification (grade), ethnicity, and selfreported GPAs to demonstrate the amount of variance explained between and within groups (Zullig, Koopman, \& Huebner, 2009). However, there has been limited research that examines how within-group differences in maternal education and academic 
achievement may manifest perceptions of school climate among homogenous populations.

Therefore, the purpose of this study was to examine differences in mother's education and self-reported academic achievement while controlling for race through paired comparisons of School Climate Measure (SCM) (Zullig, et al., 2010 \& 2015) means from a sample of Appalachian youth in West Virginia. 


\section{Chapter 2}

\section{Literature Review of School Climate and Contextual Characteristics}

\section{A Brief History of School Climate}

Quantifying the unique characteristics of schools and their effects on student outcomes can trace its roots back over a century (Thapa, Cohen, Guffey, \& HigginsD'Alessandro, 2013). However, attempts to scientifically explain the concept of school climate were not undertaken until the 1950's and 60's (Zullig, Koopman, Patton, \& Ubbes, 2010). A push for school climate research found its beginnings through organizational studies, which eventually migrated into school settings to investigate and explain variability in academic achievement (Purkey \& Smith, 1983). Therefore, defining school climate is difficult. For example, Healthy People 2020 goals are related to the tangible physical environment (including ventilation issues, clean air, pesticides, and drinking water) (US Department of Health and Human Services [DHHS], 2016). As such, researchers have posited multiple underlying variables as to what constitutes an accurate measure. These inconsistencies are markedly seen in the literature ranging from conceptual to circumstantial with evidence represented both anecdotally and empirically (Zullig, Koopman, Patton, \& Ubbes, 2010). In contrast to Healthy People 2020, The Centers for Disease Control and Prevention (CDC) (2009a) states school climate is centered around a "positive school environment" and characterized by caring and supportive interpersonal relationships; opportunities to participate in school activities and decision-making; and shared positive norms, goals, and values (Battistich \& Hom, 1997; Wilson, 2004). Similarly, Cohen, McCabe, Michelli and Pickeral (2009), suggest school climate "refers to the quality and character of school life. School climate is based on patterns of people's experiences of school life and reflects norms, goals, values, interpersonal relationships, teaching and learning practices, and organizational structures" (p. 10). Notably, these definitions take into account social and physical dimensions of school climate and purports that a school, beyond bricks and mortar, can be a measurable unit (Zullig et al., 2010). 
In recent decades, educational systems have continued to study school ecology in various forms in an attempt to find links between demographic factors, physical environment, and student achievement (Hopson, Schiller, \& Lawson, 2014). For example, a study conducted by Zullig et al., (2010) discusses the history of school climate and representative milestones in the advancement of school climate research, including, but not limited to, the importance of student perceptions of the schools social environment (Brookover et al., 1978). Additionally, Zullig and colleagues (2010) also suggest from their review that school climate is historically comprised of five primary domains: order, safety, and discipline; academic outcomes; social relationships; school facilities; and school connectedness (see Figure 1).

\section{Domains of School Climate}

As researchers continue to develop a common definition of school climate, there has been a shift from viewing schools as strictly physical environments (Zullig, et al., 2014). Rather, school climate is a subjective experience, which includes feelings of security, perception of social relationships, and personal growth of the individual that they harbor the rest of their lives. For example, Cohen et al. (2009, p. 182), describes a positive school climate as one that, “... fosters youth development and learning necessary for a productive, contributive, and satisfying life in a democratic society." Although agreement on which variables are considered most important is debatable, instruments that have undergone psychometric testing have elucidated several common contextual domains (Order, Safety, Discipline, Academic Outcomes, Social Relationships, School Facilities, and School Connectedness) and shown to explain a large portion of variance while producing adequate reliability and validity scores among students samples (Zullig, et al., 2015). Background and definitions are presented below. Order, Safety, and Discipline

Feeling safe at school is fundemental to student learning (Peguero \& Bracy, 2015; Devine \& Cohen, 2007). Research has shown that students who feel unsafe at school have higher levels of psychological distress and are at greater risk of doing poorly at academic tasks (Glew, Fan, Katon, \& Rivara, 2008). Schools shown to have low positive school climate have greater levels of aggression, bullying (Melton et al., 
1998), and violence (Wilson, 2004). In addition, schools that lack supportive norms, structures, and relationships are more often accompanied by high levels of absenteeism and lower academic achievement (Astor, Guerra, \& Van Acker, 2010; Thapa et al., 2013). As such, students in schools that used consistent equitable enforcement of school policy with the accessibility of caring adults were perceived to be safer (Gregory, Cornell, \& Fan, 2012). It is clear that students feeling safe is an essential component of measuring school climate and ultimately student success (Furlong, Greif, Bates, Whipple, \& Jimenez, 2005).

\section{Academic Outcomes}

Setting and achieving goals is a fundamental human need (Maslow, 1943). With students spending a large portion of their time in school, development of selforganizational skills is often a requirement for academic success and achievement (Zullig, et al, 2011). Academic outcomes provide students with a sense of accomplishment, recognition, and overall satisfaction with classes and school (Thapa, et al., 2013). Research has shown that if students perceive they have the confidence to do well and enjoy learning the content of a subject, they are more likely to be academically successful. A good portion of this is facilitated through positive teaching and cohesive peer environments (Thapa et al., 2013). Achieving positive academic outcomes may be a student by student endeavor, but ensuring all students have an equal chance at success comes from understanding how academic outcomes contribute to the overall school climate.

\section{Social Relationships}

Schools play a major role in children's development of social relationships outside of the direct family (Hopson, Schiller, \& Lawson, 2014). How a school's climate is applied and structured is often an antecedent to social and emotional perceptions carried into adulthood (Cohen et. al., 2009). Students engaged in positive relationships with teachers and school staff tend to feel more socially linked and participate less in risky and troublesome behaviors (Crosnoe, 2004; McNeely, Nonnemaker, \& Blum, 2002; Hopson, Schiller, \& Lawson, 2014). According to Thapa et al. (2013) teaching and learning are deeply related. When people in schools feel related with one another and 
share in positive experiences, social and emotional norms become establish. This subsequently fosters a place for enhanced learning which leads to better academic outcomes. Research suggests social relationships are crucial for the development of students throughout their school experience (Hamre \& Pianta, 2001; Thapa et al., 2013). Just as positive relationships support the development of overall student wellbeing and academic outcomes, negative or conflicting experiences can have a polarizing effect and lead to disruptive student behavior, depression, and unfavorable academic outcomes (Jia et al., 2009; Skinner \& Belmont, 1993). Simply put, when a school's social environment is not conducive to form positive relationships, it puts a student's social and emotional well-being at risk.

\section{School Facilities}

Understanding the importance of ecological influences on learning has been well documented (Roskos \& Neuman, 2011). The physical space (e.g. school grounds \& classroom décor) devoted to learning is as influential as the social norms, perceived safety, and emotional support associated to a student's academic achievement and perception of school climate. A clean and presentable space (e.g. free of trash, deteriorated fixtures, graffiti, etc.) helps with a sense of safety and prevents accidental injury (CDC, 2001). When school grounds are free of physical dilapidation, students are less likely to engage in behaviors related to social disorder (Plank, Bradshaw, \& Young, 2009). For example, Bradshaw et al. (2014), reported that student's ability to learn is more likely to be hindered among schools with a presence of social disorder. Likewise, even classroom arrangement (e.g. seating position) has been reported to have an effect on student learning outcomes (Cleveland \& Fisher 2014; Weinstien, 1979). Although many gaps still exist on just how facilities support learning, it has been found school climate acts as a mediating role in the quality of the physical environment of a school (Uline \& Tschannen-Moran, 2008).

\section{School Connectedness}

According to the CDC (2009c), students are better prepared to engage in positive health related behaviors and succeed at higher levels academically when they feel connected to their school. For example, The National Longitudinal Study of Adolescent 
Health investigated which protective factors affect overall adolescent health and wellbeing (Centers for Disease Control and Prevention (CDC), 2009c; Resnick, et al., 1997; Resnick, Harris, and Blum, 1993; Nonemaker, McNeeley, Blum, 2003). Among all the protective factors assessed (family, school, and individual factors) results concluded school connectedness was the most profound for both males and females in the reduction of substance use, school absenteeism, early sexual initiation, violence, and risk of unintentional injury (e.g. not using seat-belts) (Resnick, et al., 1997). In addition, research has established positive associations with school connectedness and progressive educational outcomes among individual-level predictors (Fan, Williams, \& Corkin, 2011). These studies and others have shown, and continue to support the notion, that when students do well in school they are less likely to take part in risky behaviors that may affect overall health and well-being. (CDC, 2009a; Hawkins, 1997).

\section{Study Hypothesis}

The literature described in this thesis suggests five common contextual domains represent a foundational core for the majority of school climate research. From most studies, samples reported similar variances between respondents (main effects), but with subtle differences between demographic variables (interactions). Noting these differences provides stakeholders the luxury of comprehensive data-driven decisions, which may have implications for positive educational strategies and student outcomes. However, most instruments over the past decade are considered unidimensional with limited psychometric support. Regions of the U.S. like Appalachia, specifically West Virginia, with its socio-economic and cultural distinctiveness may require additional strategies to mitigate potential educational issues (e.g. lower graduation rates and higher rates of families in poverty). With the ESSA beginning to modify several aspects of how a school's quality and student outcomes are measured, there is a present need for comprehensive multidimensional assessment. Therefore, the present study hypothesized that students who reported lower levels of maternal education, grades is mathematics, and/or grades in English would report lower perceived school climate scores. Specifically, this investigation was undertaken to provide a preliminary 
descriptive exploration of mean scores of school climate among a homogenous group of high school students from West Virginia. 


\section{Chapter 3}

\section{Methods}

\section{Research Questions}

The following research question(s) were developed to guide this study's hypothesis using a sample from two high schools located in West Virginia.

1. Is there a difference between perceived school climate by mother's education while controlling for race among West Virginia public high school students?

2. Is there a difference between perceived school climate by self-reported grades: mathematics while controlling for race among West Virginia public high school students?

3. Is there a difference between perceived school climate by self-reported grades: English while controlling for race among West Virginia public high school students? 


\section{Participants}

A total of 2,040 students enrolled in grades 9 - 12 were surveyed using crosssectional purposeful cluster sample from the two high schools. School 1 consisted of 1,605 enrolled students with a final sample of 1,000 students and a response rate of $62.3 \%$. School 2 consisted of 435 enrolled students with a final sample of 325 . The total aggregate sample consisted of 1,325 respondents from both schools with a $64.6 \%$ response rate. Data cleaning procedures removed 50 (3.8\%) of responses: eight $(.60 \%)$ due to double entries, $14(1.05 \%)$ due to $15 \%$ or less of the questionnaire being answered, two (.15\%) for evidence of systematic answering (a conflict in logic), and 26 $(1.96 \%)$ due to having used all substances $40 x+$ during the last 12 months. Final total number of respondents after cleaning equaled 1,275.

\section{Procedures}

In the fall of 2014, researchers at West Virginia University School of Public Health embarked on a project that focused to strengthen protective factors and reduce risk factors for substance use, teen parenting, and school drop-out rates at two high schools in West Virginia. The theoretical underpinnings and design of the initiative is analogous with that of the Icelandic Model described elsewhere by Sigfusdottir et al. (2009) and data collection procedures described by Kristjansson, et al., (2013). With financial support from The Sisters of Saint Joseph's Charitable Fund, the Integrated Community Engagement (ICE) collaborative survey was constructed to collect information from four domains: 1) parents and family, 2) the school, 3) friends and peers, and 4) leisure time. The School Climate Measure (SCM) developed by Zullig and colleagues (2015) provides the multidimensional measure to describe characteristics of the schools using ten domains. Specific item wording can be found in Table 2 (Zullig et al., 2015).

Each school was assigned a supervising contact agent (SCA) to administer the data collection protocol designed by the ICE collaborative team. Data was collected using an anonymous paper-and-pencil or web-based questionnaire, which has been shown to have little difference in quality response rates among adolescents (Wyrick \& Bond, 2011). A passive consent method was employed by sending a note home with 
students to give to their parents or caregivers. Participation was voluntary and made available to all students. Students were free to answer all or part of the survey and opt out of participation at any time. Surveys took an average of 30 to 45 minutes to complete. Students were instructed not to write their names or any other identifying information on the questionnaire or accompanying envelope. Schools and SCA were provided a small dollar amount as an incentive for their time and participation. All aspects of the data collection were approved by West Virginia University Institutional Review Board (protocol \# 1406345394A001).

\section{Measures}

Dependent Variable

The School Climate Measure (SCM). Until recently, few studies have been conducted using scientifically validated multidimensional instruments to measure perceptions of school climate (Cohen et al., 2009; Zullig, Collins, Ghani, Hunter, Patton, Huebner, \& Zhang, 2015).

A collection of works by Zullig and colleagues (2010, 2014, \& 2015) describe the psychometric exploration of the School Climate Measure (SCM) beginning with a foundational pilot by Zullig et al., (2010) through a series of the testing phases among demographically heterogeneous samples (Zulling et al, 2014, \& 2015). The guiding principal of the SCM is to produce the most complete and useful information while keeping the scope of the measure in mind (Zullig et al., 2015). Based on this notion, the SCM may be used to facilitate data-informed decisions and further outline recommendations for potential evidence-based procedures for improved school quality (Zullig, Huebner, \& Patton, 2011). Nevertheless, despite its strengths, additional research with additional samples is needed to further refine the SCM.

The SCM contains 42 items assessing ten subscales (domains); positive studentteacher relationships, order and discipline, opportunities for student engagement, school physical environment, academic support, parental involvement, school connectedness, perceived exclusion/privilege, school social environment, and academic satisfaction. Survey respondents are asked to indicate how much they agree or 
disagree with the item statements on a 5-point Likert scale from "Strongly Disagree" (Coded 1) to "Strongly Agree" (Coded 5).

Independent Variables

Mother's Education. Mother's education was captured by respondents selecting one entry from a singular question "What is the highest level of schooling your mother has completed?" Response options were "I don't know/Doesn't apply," "Graduated with a Master's, Doctorate, or Professional Degree," "Graduated from a university or 4-year college," "Started university or 4-year college but has not finished," "Graduated from junior college or trade school," "Started junior college or trade school but has not finished," "Graduated from high school," "Started high school but has not finished," and "Elementary or middle school or less".

To simplify statistical analysis and reporting, "Graduated Master's ...," "Graduated 4-year College ...," and Graduated junior college ...,", were combined into "Graduated College". "Graduated from high school," Started 4-year College . ..," and Started junior college ...," were combined into "Graduated high school". "Started high school . ..," "Elementary or middle ...," were combined into "Less than high school", and "I don't know ...," was included as its own group.

Academic Performance. The ICE instrument asked respondents to self-report their grades in Mathematics and English with the question "What were your FINAL grades in the following subjects LAST year?" Response options were "A's", "B's", "C's", "D's", and "F's". For analysis and reporting, the academic response levels were combined to make "A's/B's" and "D's/F's". "C's" were left unchanged. In addition, an "unsure" category was added to account for missing or unknown responses for descriptive analyses.

\section{Control Variable}

Race. Respondents were asked indicate their race with the question "How do you describe yourself?" Respondents could select all that applied to them from seven responses. Items for Race composed of "American Indian or Native American," "Asian," "Black or African American- not Hispanic," "Hispanic or Latino," "Native Hawaiian or 
Other Pacific Islander," "White," and "Other". For analysis and reporting, the sample was dichotomized into being "White" or "All other races" owing to the small sample size of students who reported their race as other than "White". Lastly, an "unsure" category was added to account for missing or unknown responses for descriptive analyses.

\section{Statistical Analysis}

All analyses will be conducted in SAS 9.4 (SAS institute Inc., 2000-2012). Of particular note, SAS by default uses pairwise deletion. It is recommended any amount over $5 \%$ of data missing should consider a form of imputation. Due to solidarity of the data, it was best to make mention and that the default settings were in SAS 9.4 were chosen and imputation was not be utilized (SAS Institute Inc., 2000-2012).

Descriptive Statistics. Univariate analyses were used to describe SCM and Domain means as continuous variables assessing normality, mean, median, mode, skewness, kurtosis and other descriptive statistics. Frequencies were used to analyze the discrete (categorical) variables of sex, race, academic performance (Mathematics and English), and mother's education. Any major outliers found were considered for deletion if correction was not an option.

Factorial ANCOVA. A factorial analysis of co-variance was performed using the Proc GLM procedure to examine main and interaction effects between the independent (mother's education and grades) and dependent variable (instrument mean) variables, while controlling for race. Specifically, a $3 \times 3 \times 4$ within-group analysis of co-variance to test differences in School Climate Measure score means in relation to mother's education and grades (Mathematics and English) and the interactions of these variables (e.g. mother's education X math, mother's education X English, and mother's education $X$ race). Differences in means were examined using the Tukey-Kramer Adjustment test at a statistical significance level of .01 using the LSMEANS statement. Lastly, Cohen's $f$ effect sizes were calculated to better understand the practical importance of the linear model and independent variables. Cohen's $f$ are small $=0.10$, medium $=0.25$, large $=$ 0.40 (Cohen, 1992). 


\section{Chapter 4}

\section{Results}

\section{Descriptive Statistics}

Descriptive statistics for study variables are reported in Table 1. The total sample consisted of 554 males (43.5\%), 708 females (55.5\%), and $13(1 \%)$ reported they were unsure. The sample was homogeneous with most students reporting White-Non Hispanic 1,157 (90.8\%), with an additional 107 (8.4\%) being pooled into all other races and ethnicities, and $11(0.9 \%)$ reporting unsure. The present sample accurately represents the $9-12$ grade population in the state of West Virginia (WVDOE, 2015).

Most students reported mostly A's/B's in Mathematics 840 (65.88\%) and English 974 (76.39\%). For mother's education, most students were categorized into college graduate 495 (38.82\%) and high school graduate 384 (30.12\%) with "I don't know" reporting counts of 255 (20.00\%) and less than high school with 71 (5.57\%).

Participants reported an average mean SCM score of $3.09(S D=0.69)$ which suggests most students had a neutral perception of school climate within this sample. The distribution of scores were generally centralized with only a slight negative skew (0.82 ) with more values above the mean and slightly leptokurtic (1.69) giving the curve a slight peak. The minimum value (0.19) and the maximum (5) were respectively distant with a range value of 4.8 .

\section{Instrument Test Statistics}

Internal reliability. Cronbach's alpha (Cronbach, 1951) was used to provide instrument internal consistency ( $\alpha=.94$ ) estimation and elucidate items that may cause factor suppression. Additionally, coefficient alphas ranged from .75 to .95 for each of the SCM domains and are reported in Table 2.

Confirmatory factor analysis. Confirmatory factor analysis (CFA) was then performed on all $10 \mathrm{SCM}$ constructs to determine instrument performance and model fit in this sample. Because aspects of model fit is determined by multiple indices, researchers often report two absolute fit statistics: standard root mean residual (SRMR), 
root mean square error approximation (RMSEA) with values <.05. Additionally, to indicate incremental fit, the comparative fit index (CFI) and Tucker-Lewis index (TLI) with values $>.95$ are reported (Hu \& Bentler, 1999). Analyses confirmed the 10 domains fit the data well $X^{2}=2364.73$ ( $\mathrm{df}=774, p=<.0001$ ), comparative fit index $(\mathrm{CFI})=.95$, Tucker-Lewis index $(T L I)=.94$, root mean square error of approximation (RMSEA) $=.040( \pm .038, .042)$. The goodness-of- fit index was .91 . Factor loadings ranged from .63 to .94 . Specific loadings are reported in Table 2.

Lastly, bivariate correlations between the SCM domains and total SCM scaled score mean ranged from .20 (Perceived Exclusion) to .79 (Opportunities for School Engagement) with a mean of 0.59 correlation (all $p<.0001$ ). These correlations indicate the domains are related but distinguishable from each other. Additionally, the variance inflation ranged from 1.013 (race) to 1.20 (math) confirming there was no issues with multicollinearity.

\section{Inferential Statistics}

Bivariate relationships between variables were examined to check for model correctness. Spearman's rank correlation was used to test the strength of relationships among our dependent variable, independent variables, and the covariate. Our correlational analysis reported weak, but statistically significant positive correlations between Mathematics $\left(r_{s}=0.13, p=<.0001\right)$, English $\left(r_{\mathrm{s}}=0.11, p=<.0001\right)$, mother's education ( $r_{s}=0.12, p=<.0001$ ), and the SCM mean score. There was also a nonsignificant negative correlation between race $\left(r_{s}=-0.02, p=0.4072\right)$, and the SCM mean score.

During initial testing of the linear model interactions between mother's education $X$ math, mother's education $X$ English and math $X$ English were found to be insignificant and interfered with model correctness and parsimony. Therefore, these interactions were removed from the model. Our full analysis of covariance model produced a significant result $(F(15)=6.47, p=<.0001)$ using a 0.01 alpha level of statistical significance and reported significant main effects for Mathematics $(F=(2) 18.62, p=$ $<.0001)$ and mother's education $(F(2)=7.96, p=<.0001)$ for the SCM mean score. English $(F(2)=2.35, p=0.0958)$ had a non-significant relationship. In addition, 
mother's education $\mathrm{X}$ race $(F(2)=4.31, p=0.0049)$ and English $\mathrm{X}$ race $(F(2)=4.66, p$ $=0.0096$ ) yielded significant interactions. Mathematics $X$ race produced no significant interaction $(F(2)=0.51, p=0.6033)$.

The pairwise differences between means were compared for the SCM means score and each level of a given independent variable while controlling for race using the Tukey-Kramer Adjustment test. Overall, the test produced significant and insignificant results when testing for differences among pairs while controlling for Type 1 error (Table 3). This is not surprising given the homogeneity of the sample.

Mathematics indicated no significant difference between minority students who reported mostly D's/F's compared to minority students who reported mostly A's/B's. White students indicated a significant difference for students who reported mostly D's/F's ( $t=3.89, p=0.0015)$ compared to students who reported mostly A's/B's. These results suggest White students who reported D's/F's in Mathematics also had a lower SCM mean score compared to White students who reported earning higher grades in Mathematics. English indicated no significant differences between means for any groups.

Mother's education found significant differences between below high school and all other education levels for minority students with t-values ranging $4.79, p=<.0001$ (graduate high school) to $4.48, p=0.002$ (graduated college). Moreover, White students who indicated their mother's education was below high school $(t=3.65, p=0.006)$ were significantly different than students who indicated their mother's education was graduated from college. These results suggest students who mother's education was below a high school graduate had a lower SCM mean score than students whose maternal education was high school graduate or above. There was no statistical significance for mother's education between high school and college graduates for White or minority students.

Lastly, the full model yielded medium effect sizes $(f=0.31)$. Individual variables reported small effect sizes for Mathematics ( $f=0.17$ ), English $(f=0.01)$, and mother's education $(f=0.17)$. Pairwise group effect sizes were medium to small and are reported in Table 3. Lastly, caution on the interpretation some of the within-group effect sizes 
must be emphasized as small sample sizes tend to inflate effect size calculations (Cohen, 1992). 


\section{Chapter 5}

\section{Discussion}

School improvement and student success will continue to be topics at the forefront of educational reform and policy (OPS, 2015). With the implementation of the ESSA, schools will be held accountable for assessing, monitoring, and understanding non-academic factors in addition to mathematics and reading to evaluate a schools quality (OPS, 2015). Understanding non-academic factors like school climate can provide schools with the information needed to implement innovative/alternative pedagogical strategies to potentially reduce learning disparities, especially among disadvantaged students (Cohen, et al., 2009).

The purpose of this preliminary study was to examine differences in mother's education and self-reported academic achievement as it relates to race through paired comparisons of School Climate Measure (SCM) means (Zullig, et al., 2010 \& 2015) in a sample of Appalachian youth from West Virginia. Prior to running the analysis, a confirmatory psychometric analysis confirmed that the data fit well and the instrument was performing as expected. Overall, the analysis reported differences between student's perceived school climate means, level of mother's education, and selfreported Mathematics scores. Surprisingly, self-reported English scores did not produce a significant difference in SCM means scores.

The average sample mean did not reflect a positive or negative school climate. However, mother's education emerged as the most prominent factor in our model. Regardless of race, student's whose maternal education was less than high school were found to have a lower perception of overall school climate. This was not surprising since there is an established basis of literature to support the influence mother's education on a child's perception of school (Reynolds \& Bezruczko, 1993; Ladd, Buhs, \& Seid, 2000). Specifically, among minority students whose mother's education was less than high school, perceived school climate was found to be significantly different than college and high school graduates as well as the "I don't know" groups. Alternatively, White students were only significantly different than students whose 
maternal education was classified as college graduate. White students who indicated high school graduate or "I don't know" tended to have similar SCM mean scores as the less than high school students. This suggest that these groups may have similar characteristics as the less than high school students. Conversely, the White "I don't know" group of students may have unaccounted non-academic for factors that influence their perception of school climate, but this is somewhat speculative. For example, there may be a perceived disadvantage to disclosing maternal education as it may categorize a student to particular negative stigmas such as an indicator of SES (Brody, Stoneman \& Flor, 1995), as was the case in this study. As such, low-SES students tend to be disproportionately at risk to burden adverse living conditions outside of school (Bailey, 2013). However, a growing body of literature has suggested that schools can act as a protective factor and potentially buffer the effects of low-SES (Berkowitz et al., 2015).Therefore, assessing and attending to school climate can be used by administrators and faculty who have the ability to positively influence the lives of their students, particularly in historically disadvantaged regions like Appalachia.

Additionally, the findings among Whites reinforces the importance of understanding the characteristics of a schools population and suggests diversity within groups can easily be overshadowed when a group is demographically similar. For example, a study by Caldas \& Banskton (1997) describe the effects of SES on individual academic achievement. Their findings suggest that a student's individual background (e.g. social status, parental education, etc...) and how it may contribute to a social environment is more indicative of their academic success than racial homogeny. Based on this perspective, this further supports the differences found within White students. Specifically, students whose mother's education was college graduate were found to be significantly different than the less than high school group. It suggests that within racial homogeny, determining if students have a relative advantage or disadvantage may be contingent upon their socio-economic position, which in some circumstances, may be indicated through mother's education and reflected through a student's perception of school climate. This can also be seen among minorities within this sample. The minority students within the levels of college graduate, high school graduate, and "I don't know" had means that were almost identical. This perhaps 
suggests that minorities within a homogenous population may benefit due to the social context brought on by the advantages of a majority of White students (e.g. economic resources). Bringing forth these type of insights among homogenous school populations may be an approach schools could use to assuage the potential hidden negative effects of a schools climate and students who are disproportionately afflicted by their social status.

A unique contribution to the school climate literature is the assessment of academic performance by separating Mathematics and English. As the majority of literature rely on a single indicator for academic performance (e.g. GPA). Results from these analyses suggest minority students had no significant differences in either Mathematics or English between those that reported mostly A's/B's and D's/F's. In fact, contradictory to previous literature which analyzed relationships between Mathematics and school climate (Bodovski, Nahum-Shani, \& Walsh, 2013), minorities in this sample indicated to have a positive perception of school climate. This may be a sign of academic resilience among minorities, which has been shown to manifest itself out of supportive school social environments (Borman \& Overman, 2004). Further, research by Finn \& Rock (1997) suggest, regardless of race, students who actively participate and take interest in classroom and school activities tend to build academic resiliency. These findings support this notion through the generally positive perception of school climate among minorities. However, given that minority students in this population represent a small portion of the sample, results must be interpreted cautiously.

On the other hand, White students who reported D's/F's in Mathematics had significantly lower perceptions of school climate than White students who reported A's/B's. The White within-group comparisons speculate there also may be other nonacademic factors influencing student's perception of school climate. For example, research by Cleveland et al. (2012) describe in detail the uniqueness of school culture among Appalachian students. Their study suggests that Appalachian schools tend to lack proactive community engagement and "culturally responsive pedagogy" among teachers. This potentially leaves struggling students with limited support as teachers may be unable to recognize the need to make adjustments for a more effective 
instructional strategy. Moreover, continuing on the concepts of academic resiliency and homogeny, White students from this sample may be less shielded from latent sources of adversity. This stems from the unique challenges Appalachian populations tend to burden disproportionately compared to other regions (Cleveland, et al, 2012). Although highly speculative, White students may be at a disadvantage due to a predisposed misunderstanding of relative racial privilege (Borman \& Overman, 2004). Insofar as to say, differences in perception of school climate were indicated through mathematic scores. This finding may represent a lack of academic resilience within White students, which is supported through the difference between academic performances. Based on this idea, the findings from this study may serve as a basis for school administrators to encourage different approaches to help struggling students. This, in turn, may improve academic performance and improve perceptions of school climate and the overall quality of a school.

\section{Limitations}

Study limitations are noted here. First, the study used a predominantly homogenous White sample of Appalachian youth. Therefore, the small number of minorities may not be representative of all Appalachian minorities. The findings from this study should be assessed with other students from Appalachian settings to make generalizable inferences. Second, because this was preliminary study describing the differences in means, a study using tests of prediction may be useful to describe the power of relationships between variables. This may support further refinement of a model for future research. Third, only the overall SCM mean score was analyzed. Future research should exploring mean differences among each SCM domain, especially given their varying strength with the overall SCM mean score in the bivariate analyses. It is possible that some of the findings here could be much stronger or weaker when analyses are repeated by domain. This information could then be used to help schools refine specific areas rather than school climate as a single construct. Lastly, all data were self-reported and therefore may potentially be subject to bias. 


\section{Conclusion}

This preliminary study indicated that among this sample of Appalachian youth, unique differences were revealed within-groups regarding maternal education and academic performance as it relates to school climate. Specifically, mother's education and self-reported academic scores in Mathematics play a role in indicating how students perceive the climate of the school, which suggests that the assessment of school climate matters and is related to maternal education and academic outcomes among these students. Of particular importance are the effect sizes between White and minority student's maternal education and perceived school climate. Although caution must be emphasized in interpreting these values due to sample size as they relate to the minority students, these findings underscore the importance of contextual factors inside and outside of school. Additionally, study findings lend new insight into within group variation among seemingly homogenous Appalachian populations. With the coming changes brought on by the ESSA, it will be essential for schools to have access to useful tools that inform them about both academic and non-academic factors. Thus, instruments like the School Climate Measure may help provide information needed to address the requirements of federal legislation as well as a better understanding between school perception and school experiences. Given the similar differences between the within-groups analysis, further studies with similar methods may point to important implications for the delivery of instruction and school-based interventions that promote additional positive learning and school quality to underserved regions like Appalachia. 


\section{Tables and Figures}

Figure 1

Historically Common School Climate Domains

Domain

Domain Variations

1. Order, Safety, \& Discipline

Perceived safety

Respect for peers and authority

Knowledge and fairness of disciplinary policies

Presence of gangs

2. Academic Outcomes

Accomplishment and recognition

Sense of academic futility

Academic norms

Academic instruction

Overall satisfaction with classes

Future and present evaluations of performance

3. Social Relationships

Teacher student relationships

Interpersonal relationships

Student-peer relationships

Helpfulness of school staff

4. School Facilities

School temperature

Classroom arrangement

Ambient noise

School, classroom, and grounds conditions

School decorations

5. School Connectedness

Excited, enthusiastic, and engaged learners

Feelings about school

Students feel valued for their input

Adapted from Zullig et al., 2010 
Table 1

Sample Characteristics for All Study Variables

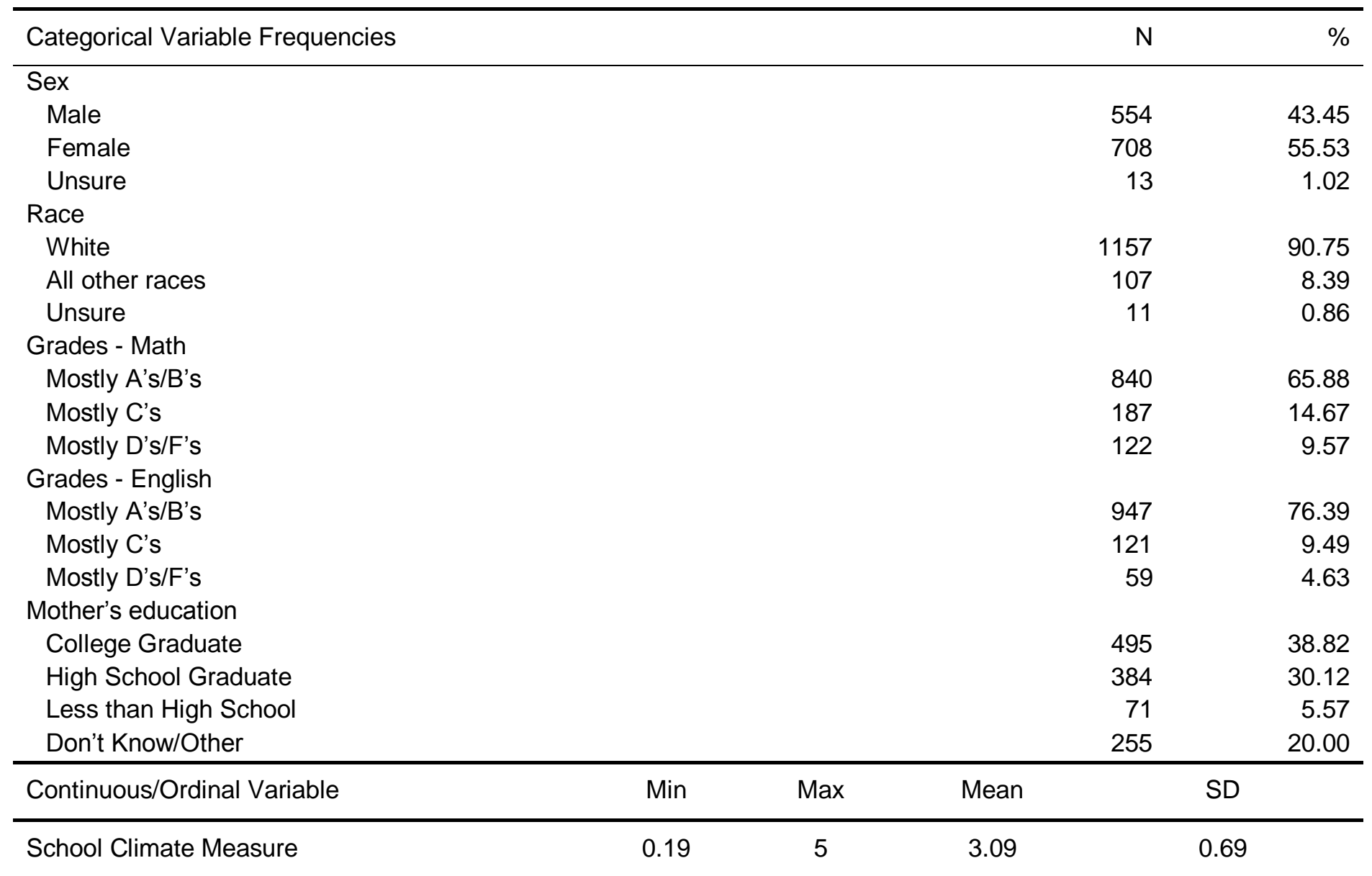

Table 2

SCM Items, Alpha Coefficients, and Factor Loadings

\begin{tabular}{lc}
\hline & \multicolumn{1}{c}{ Item (\% variance explained from Exploratory Factor Analysis) } \\
Factor 1: Positive Student - Teacher Relationships (17.9\%) & .86 \\
Teachers understand my problems & .72 \\
Teacher and staff seem to take a real interest in my future & .80 \\
It is easy to talk with teachers & .80 \\
Students get along well with teachers & .78 \\
Teachers at my school help us children with our problems & .69 \\
My teachers care about me & .86 \\
My teacher makes me feel good about myself & .86 \\
Factor 2: Order, Safety, and Discipline (21.8\%) & .89 \\
Classroom rules are applied equally & .78 \\
Problems in this school are solved by students and staff & .75 \\
The rules of the school are fair & .81
\end{tabular}


School rules are enforced consistently and fairly .81

My teachers make it clear to me when I have misbehaved in class .63

Discipline in fair 79

Factor 3: Opportunities for Student Engagement (10.5\%)

Student have the same opportunity in class to speak, and be listened to .79

Students can express feelings and thoughts about school, work, and life .79

Students "different" in any way are treated with respect $\quad .76$

Nobody in my school is excluded from being successful $\quad .76$

Females and male are treated as equals at school .72

I can participate in a lot of interesting activities in school .69

Factor 4: School Physical Environment (8.8\%) .95

The school ground are kept clean .87

My school is neat and clean .92

My school buildings are generally pleasant and well maintained .90

My school is usually clean and tidy .94

Factor 5: Academic Support (11.8\%) $\mathbf{. 8 4}$

I usually understand my homework assignments .74

Teachers make it clear what work needs to be done to get the grade I want .77

I believe that teacher expect all student to learn .73

I fell that I can do well in this school 76

Factor 6: Parent Involvement (8.7\%)

My parents/caregivers talk with teachers about what is happening at home .72

My parents/caregivers are involved in school activities .74

My parent/caregivers are involved in discussions about what is taught at school .83

Factor 7: School Connectedness (5.7\%)

My schoolwork is exciting $\quad .72$

Students can make suggestions on courses that are offered .73

This school makes students enthusiastic about learning .87

Students are frequently rewarded or praised by faculty and staff for following school rules .72

Factor 8: Perceived Exclusion/Privilege (4.9\%) $\mathbf{9 0}$

At my school, the same person always gets to help the teacher .82

At my school, the same students get chosen every time to take part in after-school or special .93

The same students always get to use things, like a computer, a ball, or piano, when we interact 86

Factor 9: School Social Environment (11.3\%)

I am happy with the kinds of students who go to my school .88

I am happy, in general, with the other students who go to my school .89

Factor 10: Academic Satisfaction (3.9\%)

I am happy about the number of test I have .82

I am happy about the amount of homework I have .72

Note: Cronbach's alpha is reported in boldface. \% variance explained from weighted communality estimates. 
Table 3

Pairwise Analysis of School Climate Measure: Means, Standard Deviations, and Effect Sizes

\begin{tabular}{|c|c|c|}
\hline & White Students & Minority Students \\
\hline & $M(S D)$ & $M(S D)$ \\
\hline \multicolumn{3}{|l|}{ Self-Reported Grades: Math } \\
\hline \multirow[t]{2}{*}{ Mostly A's/B's } & $3.05(1.22)$ & $3.35(1.36)$ \\
\hline & $n=745$ & $n=63$ \\
\hline \multirow[t]{2}{*}{ Mostly C's } & $2.99(0.74)$ & $3.32(0.84)$ \\
\hline & $n=169$ & $n=14$ \\
\hline \multirow[t]{3}{*}{ Mostly D's/F's } & $2.77(0.62)^{\star * *}$ & $2.86(0.66)$ \\
\hline & $n=102$ & $n=17$ \\
\hline & $f=.11$ & $f=.17$ \\
\hline \multicolumn{3}{|c|}{ Self-Reported Grades: English } \\
\hline \multirow[t]{2}{*}{ Mostly A's/B's } & $3.05(0.98)$ & $2.79(0.91)$ \\
\hline & $n=861$ & $n=76$ \\
\hline \multirow[t]{2}{*}{ Mostly C's } & $2.96(0.62)$ & $3.06(0.66)$ \\
\hline & $n=103$ & $n=14$ \\
\hline \multirow[t]{3}{*}{ Mostly D's/F's } & $2.81(0.63)$ & $3.68(0.70)$ \\
\hline & $n=52$ & $n=4$ \\
\hline & $f=0.10$ & $f=.41$ \\
\hline \multicolumn{3}{|l|}{ Mother's Education } \\
\hline \multirow[t]{2}{*}{ College Grad } & $3.06(0.94)$ & $3.39(0.97)$ \\
\hline & $n=414$ & $n=40$ \\
\hline \multirow[t]{2}{*}{ High School Grad } & $2.97(0.83)$ & $3.53(0.88)$ \\
\hline & $n=324$ & $n=23$ \\
\hline \multirow[t]{2}{*}{ Less than High School } & $2.78(0.66)^{\star \star \star}$ & $2.26(0.70)^{\star \star \star}$ \\
\hline & $n=82$ & $n=7$ \\
\hline \multirow[t]{3}{*}{ Doesn't Know } & $2.94(0.71)$ & $3.51(0.77)$ \\
\hline & $n=196$ & $n=24$ \\
\hline & $f=.12$ & $f=.51$ \\
\hline
\end{tabular}

Cohen's $f$ are small $=0.10$, medium $=0.25$, large $=0.40$ (Cohen, 1992).

${ }^{*} p<.05{ }^{* * *} p<.01$

Note: means denoted by race. 


\section{References}

Appalachia Regional Advisory Committee (Appalachia RAC). (2011). Appalachian Region: A Report Identifying And Addressing The Educational Needs. U.S. Department of Education Regional Advisory Committee (RAC). Washington, DC

Appalachia Community Cancer Network. (2010). Addressing the cancer burden in Appalachian communities 2010. National Cancer Institute. Retrieved from: http://www.accnweb.com/pages/cancer-burden-app.pdf

Astor, R. A., Guerra, N., \& Van Acker, R. (2010). How can we improve school safety research? Educational Researcher, 39, 69-78.

\section{http://dx.doi:10.3102/0013189X09357619}

Bandura, A. (2001). Social cognitive theory: An agentic perspective. Annual review of psychology, 52(1), 1-26.

Battistich, V., Hom, A. (1997). The relationship between students' sense of their school as a community and their involvement in problem behaviors. American Journal of Public Health 87(12):1997-2001.

Baily, L. (2014). A Review of the Research: Common Core State Standards for Improving Rural Children's School Readiness. Early Childhood Education Journal, 42, 389-396. http:dx.doi.10.1007/s10643-013-0621-6

Behringer, B., \& Friedell, G. H. (2006). Appalachia: where place matters in health. Preventing Chronic Disease, 3(4), A113

Berkowitz, R., Glickman, H., Benbenishty, Rami., Ben-Artzi, E., Raz, T., Lipshtat, N., Astor, R. A. (2015). Compensating, Mediating, and Moderating Effects of School Climate on Academic Achievement Gaps in Israel. Teachers College Record, 117,070308

Bethea, T. N., Lopez, R. P., Cozier, Y. C., White, L. F., \& McClean, M. D. (2012). The Relationship between Rural Status, Individual Characteristics, and Self-Rated Health in the Behavioral Risk Factor Surveillance System. Journal Of Rural Health, 28(4), 327-338. 
Bodovski, K., Nahum-Shani, I., Walsh, R. (2013). School Climate and Students' Early Mathematics Learning: Another Search for Contextual Effects. American Journal of Education, 119(2), 209 - 234.

Borman, G. D., \& Overman, L. T. (2004). Academic resilience in mathematics among poor and minority students. The Elementary School Journal, 177-195.

Bradshaw, C. P., Waasdorp, T. E., Debnam, K. J., \& Johnson, S. L. (2014). Measuring school climate in high schools: A focus on safety, engagement, and the environment. Journal of school health, 84(9), 593-604.

Brody, G. H., Stoneman, Z., \& Flor, D. (1995). Linking family processes and academic competence among rural African American youths. Journal of Marriage and the Family, 567-579.

Brody, G. H., \& Flor, D. L. (1998). Maternal resources, parenting practices, and child competence in rural, single-parent African American families. Child development, 69(3), 803-816.

Brookover, W. B., Schweitzer, J. H., Schneider, J. M., Beady, C. H., Flood, P. K., \& Wisenbaker, J. M. (1978). Elementary school social climate and school achievement. American Educational Research Journal, 15, 301-318.

Caldas, S. J., \& Bankston, C. (1997). Effect of school population socioeconomic status on individual academic achievement. The Journal of Educational Research, 90(5), 269-277.

Centers for Disease Control and Prevention (CDC). (2009a). Fact sheet: Health risk behaviors and academic achievement. Atlanta, GA: U.S. Department of Health and Human Services. Retrieved from: http://www.cdc.gov/healthyyouth/health_and_academics/pdf/health_risk_behavio rs.pdf

Centers for Disease Control and Prevention (2009b). Estimated county-level prevalence of diabetes and obesity - United States, 2007. Morbidity and Mortality Weekly Report (MMRW), 58(45), 1259-1263. 
Centers for Disease Control and Prevention (CDC). (2009c). School Connectedness:

Strategies for Increasing Protective Factors Among Youth. Atlanta, GA: U.S.

Department of Health and Human Services. Retrieved from:

\section{http://www.cdc.gov/healthyyouth/protective/pdf/connectedness.pdf}

Centers for Disease Control and Prevention (CDC). (2001). School health guidelines to prevent unintentional injuries and violence. Morbidity and Mortality Weekly Report (MMWR), 50(22), 1-73.

Child, D. (2006). The essentials to factor analysis. (3rd ed.). New York, NY: Continuum International Publishing Group.

Cleveland, B., \& Fisher, K. (2014). The evaluation of physical learning environments: a critical review of the literature. Learning Environments Research, 17(1), 1-28.

Cleveland, R., Chambers, J., Mainus, C., Powell, N., Skepple, R., Tyler, T., \& Wood, A. (2012). School culture, equity, and student academic performance in a rural Appalachian school. Kentucky Journal of Excellence in College Teaching and Learning, 9(1), 4.

Cohen, J. (1992). A power primer. Psychological Bulletin, 112, 155-159

Cohen, J., McCabe, E. M., Michelli, N. M., \& Pickeral, T. (2009). School climate:

Research, Policy, Practice, and Teacher Education. Teachers College Record, 111(1), 180-213.

Cronbach, L. J. (1951). Coefficient alpha and the internal structure of tests. Psychometrika, 16(3), 297-334.

Department of Health and Human Service (DHHS). (2016). Healthy People 2020. Washington, DC: Office of Disease Prevention and Health Promotion. Retrieved from: http://www.healthypeople.gov/2020/topics-objectives/topic/environmentalhealth/objectives

Devine, J., \& Cohen, J. (2007). Making your school safe: Strategies to Protect Children and Promote Learning. New York, NY: Teachers College Press. 
Every Student Succeeds Act (ESSA), S.117, 114th Cong. (2015). Retrieved from: https://www.congress.gov/bill/114th-congress/senate-bill/1177/text

Fan, W., Williams, C. M., \& Corkin, D. M. (2011). A multilevel analysis of student perceptions of school climate: The effect of social and academic risk factors. Psychology in the Schools, 48(6), 632-647.

Finn, J. D., \& Rock, D. A. (1997). Academic success among students at risk for school failure. Journal of Applied Psychology, 82, 221-234

Food Research and Action Center. (2015). West Virginia: Demographics, Poverty, and Food Insecurity. Profile of Hunger, Poverty, and Federal Nutrition Programs. Retrieved from: http://frac.org/wp-content/uploads/2010/07/wv.pdf

Furlong, M. J., Greif, J. L., Bates, M. P., Whipple, A. D., Jimenez, T. C., \& Morrison, R. (2005). Development of the California school climate and safety survey-short form. Psychology in the Schools, 42(2), 137-149.

Gershoff, E. (2003). Low income and the development of America's kindergartners. New York: National center for children in poverty. Measuring rurality: Rural-urban continuum codes. Retrieved from: http://www.nccp.org/publications/pdf/text_533.pdf

Glanz, K., Rimer, B. K., Viswanath, K. (2008). Health Behavior and Health Education: Theory, Research, and Practice. San Francisco, CA: Jossey-Bass.

Glew, G. M., Fan, M. Y., Katon, W., \& Rivara, F. P. (2008). Bullying and school safety. The Journal of pediatrics, 152(1), 123-128.

Gordon, M., \& Cui, M. (2014). School-Related Parental Involvement and Adolescent Academic Achievement: The Role of Community Poverty. Family Relations, 63, 616-626. http://dx.doi:10.1111/fare.12090

Gregory, A., Cornell, D., \& Fan, X. (2012). Teacher safety and authoritative school climate in high schools. American Journal of Education, 118, 401-425. http://dx.doi:10.1086/666362 
Gregory, A., \& Weinstein, R. S. (2004). Connection and regulation at home and in school: Predicting growth in achievement for adolescents. Journal of Adolescent Research, 19, 405-427. http://dx.doi:10.1177/0743558403258859

Hamre, B. K., \& Pianta, R. C. (2001). Early teacher-child relationships and the trajectory of children's school outcomes through eighth grade. Child Development, 72(2), 625-638.

Haverson J, Ma L, Harner EJ. (2004). An analysis of disparities in health status and access to care in the Appalachian region. Washington, DC: Appalachian Regional Commission. Retrieved from: http://www.arc.gov/index.do?nodeld=2467\&print=yes

Hawkins, J.D. (1997). Academic performance and school success: sources and consequences. In Weissberg R. P., Gullotta T.P., Hampton R.L., Ryan B.A., Adams G.R., (Eds.), Healthy Children 2010: Enhancing Children's Wellness. (Vol 8). Issues in Children's and Families' Lives. Thousand Oaks, CA: Sage Publications.

Hopson, L. M., Schiller, K. S., \& Lawson, H. A. (2014). Exploring linkages between school climate, behavioral norms, social supports, and academic success. Social Work Research, 38, 197-209. http://dx.doi:10.1093/swr/svu017

Hoy, W. K., Tarter, C. J., \& Hoy, A. W. (2006). Academic optimism of schools: A force for student achievement. American educational research journal, 43(3), 425-446.

Hu, L., \& Bentler, P. M. (1999). Cutoff criteria for fit indexes in covariance structure analysis: Conventional criteria versus new alternatives. Structural Equation Modeling, 6(1), 1-55. http//:dx.doi:10.1080/10705519909540118

Illeris, K. (2004). The three dimensions of learning. Malabar, FL: Krieger Publications.

Ingram D. D., Franco S.J. (2012). NCHS urban-rural classification scheme for counties. National Center for Health Statistics, Vital Health Statistics, 2(154).

Istrate, O., Noveanu, G., \& Smith, T. M. (2006). Exploring sources of variation in Romanian science achievement. Prospects, 36(4), 475-496. 
Ito, A., \& Smith, D. C. (2006). Predictors of school satisfaction among Japanese and U.S. youth. The Community Psychologist, 38, 19-21.

Jackson, A. W., \& Davis, G. A. (2000). Turning points 2000: Educating adolescents in the 21st century. Williston, VT: Teachers College Press.

Jia, Y., Way, N., Ling, G., Yoshikawa, H., Chen, X., Hughes, D., \& Lu, Z. (2009). The influence of student perceptions of school climate on socio-emotional and academic adjustment: A comparison of Chinese and American adolescents. Child Development, 80, 1514-1530. http://dx.doi:10.1111/j.14678624.2009.01348.x

Kristjansson, A. L., Sigfusson, J., Sigfusdottir, I. D., \& Allegrante, J. P. (2013). Data collection procedures for school-based surveys among adolescents: The Youth in Europe Study. Journal of School Health, 83(9), 662-667.

Ladd, G. W., Buhs, E. S., Seid, M. (2000). Children's Initial Sentiments About Kindergarten: Is School Liking and Antecedent of Early Classroom Participation and Achievement?. Merrill-Palmer Quarterly, 46(2), 255-279.

Lee, J. (2002). Racial and ethnic achievement gap trends: Reversing the progress toward equity? Educational Researcher, 31(1), 3-12.

\section{http://dx.doi:10.3102/0013189X031001003}

Lleras Christy. 2008. "Race, Racial Concentration, and the Dynamics of Educational Inequality across Urban and Suburban Schools." American Educational Research Journal, 45(4), 886-912.

Mann, M. J., Kristjansson, A. L., Sigfusdottir, I. D., \& Smith, M. L. (2014). The Impact of Negative Life Events on Young Adolescents: Comparing the Relative Vulnerability of Middle Level, High School, and College-Age Students. Research In Middle Level Education Online, 38(2), 1-13.

Martin, M. W., Martin, S., \& Rosengard, P. (2010). PE2GO: Program Evaluation of a Physical Activity Program in Elementary Schools. Journal of Physical Activity \& Health, 7(5), 677- 684. 
Maslow, A. H. (1943). A Theory Of Human Motivation. Psychological Review, 50(4), 370.

Meacham S, Sukpraprut S, Taber T, Metzger D. (2012). Publications on chronic disease in coal dependent communities in Central Appalachia. Journal of Health Disparities Respiratory Practice 5(3), 62-79.

Melton, G. B., Limber, S., Flerx, V., Cunningham, P., Osgood, D. W., Chambers, J., \& Nation, M. (1998). Violence among rural youth (Final report to the Office of Juvenile Justice and Delinquency Prevention). Washington, DC: U.S. Department of Justice, Office of Justice Programs, Office of Juvenile Justice and Delinquency Prevention.

Mueller, K. J., Ortega, S. T., Parker, K., Patil, K., \& Askenazi, A. (1999). Health status and access to care among rural minorities. Journal of Health Care for the Poor and Underserved, 10(2), 230-249.

Nonnemaker, J., McNeely, C., \& Blum, R. (2003). Public and Private Domains of Religiosity and Adolescent Health Risk Behaviors: Evidence from the National Longitudinal Study of Adolescent Health. Social Science \& Medicine, 57, 2049 2054.

No Child Left Behind Act (NCLB). (2001). S107, 107th Cong. Retrieved From: http://www2.ed.gov/nclb/landing.jhtml

Office of the Press Secretary. (2015, December, 2). Fact Sheet: Congress Acts to Fix No Child Left Behind. The White House, Statements and Releases. Retrieved from: https://www.whitehouse.gov/the-press-office/2015/12/03/fact-sheetcongress-acts-fix-no-child-left-behind

O’Malley, M., Voight, A., Renshaw, T. L., \& Eklund, K. (2015). School climate, family structure, and academic achievement: A study of moderation effects. School Psychology Quarterly, 30(1), 142-157. http://dx.doi:10.1037/spq0000076

Ormrod, J. (2012). Human Learning (6th ed.). Boston, MA: Peason. 
Park, N., \& Huebner, E. S. (2005). A Cross-Cultural Study of the Levels and Correlates of Life Satisfaction among Adolescents. Journal Of Cross-Cultural Psychology, 36, 444-456. http://dx.doi:10.1177/0022022105275961

Pebley, A. R., \& Sastry, N. (2004). Neighborhoods, poverty, and children's well-being. In K. M. Neckerman (Ed.), Social inequality (pp. 119-144). New York, NY: Russell Sage Foundation.

Peguero, A. A., \& Bracy, N. L. (2015). School Order, Justice, and Education: Climate, Discipline Practices, and Dropping Out. Journal of Research on Adolescence (Wiley-Blackwell), 25(3), 412-426. http://dx.doi:10.1111/jora.12138

Plank, S.B., Bradshaw, C.P., Young, H. (2009). An Application of "Broken Windows" and Related Theories to the Study of Disorder, Fear, and Collective Efficacy in Schools. American Journal of Education, 115(2), 227-247.

Purkey, S. C., \& Smith, M. S. (1983). Effective schools: A review. The elementary school journal, 83(4), 427-452.

Resnick, M. D. (1997a). Close ties to parents, school improve adolescents' lives. Minnesota Medicine, 80(12), 24-26.

Resnick, M. D., Bearman, P. S., Blum, R. W., Bauman, K. E., Harris, K. M., Jones, J, . . . Ireland, M. (1997b). Protecting adolescents from harm: findings from the National Longitudinal Study on Adolescent Health. JAMA, 278(10), 823-832.

Reynolds, A. J., \& Bezruczko, N. (1993). Early schooling of children at risk through fourth grade. Merrill-Palmer Quarterly, 39, 457-480.

Roskos, K., \& Neuman, S. B. (2011). The classroom environment. The Reading Teacher, 65(2), 110-114.

SAS Institute Inc. (2000-2012). SAS 9.4 Help and Documentation. Cary, NC: SAS Institute Inc.

Senate Committee On Health, Education, Labor and Pensions. (2015). The Every Child Achieves Act of 2015. Retrieved from: 
http://www.help.senate.gov/imo/media/The Every Child Achieves Act of 2015-summary.pdf

Sigfusdottir, I. D., Thorlindsson, T., Kristjansson, A. L., Roe, K. M., \& Allegrante, J. P. (2009). Substance use prevention for adolescents: the Icelandic Model. Health Promotion International, 24, 16 - 25. http://dx.doi:10.1093/heapro/dan038

Singh, G., \& Ghandour, R. M. (2012). Impact of Neighborhood Social Conditions and Household Socioeconomic Status on Behavioral Problems Among US Children. Maternal Child Health Journal, 16, S158 - S169. http://dx.doi:10.1007/s10995012-1005-z

Smith, L. H., \& Holloman, C. H. (2011). Health status and access to health care services: a comparison between Ohio's rural non-Appalachian and Appalachian families. Family And Community Health, 34(2), 102-110.

Skinner, E., \& Belmont, M. (1993). Motivation in the classroom: Reciprocal effects of teacher behavior and student engagement across the school year. Journal of Educational Psychology, 85, 571-581. http://dx.doi:10.1037//0022-0663.85.4.571

Stanley, L. R., Comello, M. G., Edwards, R. W., \& Marquart, B. S. (2008). School Adjustment in Rural and Urban Communities: Do Students from "Timbuktu" Differ from Their "City Slicker" Peers?. Journal Of Youth And Adolescence, 37(2), 225238.

Steinberg, L. (2005). Cognitive and affective development in adolescence. Trends in Cognitive Sciences, 9, 69-74. http://dx.doi:10.1016/j. tics.2004.12.005

Thapa, A., Cohen, J., Guffey, S., \& Higgins-D'Alessandro, A. (2013). A review of school climate research. Review of Educational Research, 83(3), 357-385.

The White House, Office of Press Secretary. (2015, December 2). Fact Sheet: Congress Acts to Fix No Child Left Behind. Retrieved from: https://www.whitehouse.gov/the-press-office/2015/12/03/fact-sheet-congressacts-fix-no-child-left-behind 
Uline, C., \& Tschannen-Moran, M. (2008). The walls speak: The interplay of quality facilities, school climate, and student achievement. Journal of Educational Administration, 46(1), 55-73.

United Health Foundation. (2015). America's Health Rankings: West Virginia. American Public Health Association. Retrieved from: http://www.americashealthrankings.org/WV

U.S. Census Bureau (2010). 2010 Census. Retrieved from: http://factfinder.census.gov/faces/tableservices/jsf/pages/productview.xhtml?src= CF

U.S. Census Bureau. (2014). U.S. Census Bureau: State and County Quick Facts. Retrieved from: http://quickfacts.census.gov/afd/states/54000.html

U.S Department of Education. (2016). Every Student Succeeds Act (ESSA). Retrieved from: http://www.ed.gov/essa?src=rn

Weinstein, C. S. (1979). The physical environment of the school: A review of the research. Review of Educational Research, 49(4), 577-610.

West Virginia Department of Education. (2015). West Virginia Department of Education Enrollment Summary. Retrieved from:

\section{http://zoomwv.k12.wv.us/Dashboard/portalHome.jsp}

Willms, J. D. 2006. Learning Divides: Ten Policy Questions about the Performance and Equity of Schools and School Systems. Montreal: UNESCO Institute for Statistics.

Wilson, D. (2004). The interface of school climate and school connectedness and relationships with aggression and victimization. Journal of School Health, 74(7), 293-299.

Xue, Y., Leventhal, T., Brooks-Gunn, J., \& Earls, F. J. (2005). Neighborhood residence and mental health problems of 5- to 11-year olds. Archives of General Psychiatry, 62, 554-563. 
Zullig, K. J., Collins, R., Ghani, N., Hunter, A. A., Patton, J. M., Huebner, E. S., \& Zhang, J. (2015, February 2). Preliminary Development of a Revised Version of the School Climate Measure. Psychological Assessment. Advance online publication. http://dx.doi.org/10.1037/pas0000070

Zullig, K. J., Collins, R., Ghani, N., Patton, J. M., Scott Huebner, E., \& Ajamie, J. (2014). Psychometric Support of the School Climate Measure in a Large, Diverse Sample of Adolescents: A Replication and Extension. Journal Of School Health, 84, 82-90. http://dx.doi:10.1111/josh.12124

Zullig, K. J., Huebner, E. S., \& Patton, J. M. (2011). Relationships among School Climate Domains and School Satisfaction. Psychology In The Schools, 48, 133145. http://dx.doi:10.1002/pits.20532

Zullig, K. J., Koopman, T. M., Patton, J. M., \& Ubbes, V. A. (2010). School Climate: Historical Review, Instrument Development, and School Assessment. Journal Of Psychoeducational Assessment, 28, 139-152.

http://dx.doi:10.1177/0734282909344205

Zullig, Keith J., Koopman, Thomas M., \& Huebner, E. Scott. (2009). Beyond GPA:

Toward more comprehensive assessments of students' school experiences. Child Indicators Research, 2, 95-108. http://doi.dx. 10.1007/s12187-008-9029-z

Zullig, K. J., Reger-Nash, B., \& Valois, R. F. (2012). Health Educator Believability and College Student Self-rated Health. Journal Of American College Health, 60, 296302. http://dx.doi:10.1080/07448481.2011.604368 